Original

\title{
Histological and analytical studies of a tooth in a patient with cleidocranial dysostosis
}

\author{
Yohko Fukuta, Morio Totsuka, Yoshiyasu Fukuta ${ }^{\S}$, Yasunori Takeda ${ }^{\dagger}$, Yasuo Yoshida ${ }^{\ddagger}$, \\ Jiro Niitsu* and Hirotsugu Yamamoto"
}

\begin{abstract}
Departments of Oral Diagnosis, ${ }^{\S}$ First Department of Oral and Maxillofacial Surgery and ${ }^{\dagger}$ Oral Pathology, School of Dentistry, and "Electron Microscope Laboratory, Iwate Medical University, Morioka 020-8505

*Dental Clinic, Morioka City Hospital, Morioka 020-0866

IDepartment of Pathology, Nihon University School of Dentistry at Matsudo, Matsudo 271-0061
\end{abstract}

(Received 6 October 2000 and accepted 28 February 2001)

\begin{abstract}
A histopathological and analytical study of a permanent tooth from a patient with cleidocranial dysostosis (CCD) was performed. The patient was a 47year-old woman, who had 10 erupted permanent teeth and 2 partially erupted and 19 completely impacted teeth, including supernumerary teeth. The erupted right upper premolar was extracted and observed using a light microscope and an electron probe $X$-ray microanalyzer (EPMA). Findings showed enamel hypoplasia, predominantly irregular globular dentin and Tomes' granular layer, and a complete lack of cellular cementum in the ground section. The incremental von Ebner and counter Owen lines were obscure. Comparative quantitative analysis using the EPMA showed that the quantities of calcium and phosphate were lower in the enamel and dentin than those of the control sample. (J. Oral Sci. 43, 85-89, 2001)
\end{abstract}

Key words: cleidocranial dysostosis; enamel; dentin; cellular cementum.

\section{Introduction}

Cleidocranial dysostosis (CCD) is an autosomaldominant disease characterized by developmental disturbance of the clavicles, skull, and sometimes other parts of the skeleton (1). The characteristic oral

Correspondence to Dr. Yohko Fukuta, Department of Oral Diagnosis, School of Dentistry, Iwate Medical University, 1-327 Chuo-dori, Morioka 020-8508, Japan. manifestations are failure of tooth eruption and many impacted supernumerary teeth in the permanent dentition. However, there have been only a few morphological studies of the teeth in CCD (2-9).

We report the histological features of a permanent tooth from a patient with CCD examined using light microscopy and electron probe X-ray microanalysis.

\section{Case Report}

A 47-year-old woman who had been admitted to the Orthopedic Clinic of Morioka City Hospital for bilateral surgical treatment of osteoarthritis of the hip joints was referred to the Dental Clinic for dental treatment. The patient's medical history included an appendectomy at age 15 and cesarean sections at ages 24 and 27. The patient said that her 23-year-old daughter had only several deciduous teeth, but the detailed data could not be obtained.

On general examination the patient was of short stature. Her height was $134.6 \mathrm{~cm}$ and her weight was $45.5 \mathrm{~kg}$. The patient had opposable shoulders. The middle face was hypoplastic, with frontal bossing and a broad-based nose. Radiological examination revealed partial defects of the bilateral clavicles (Fig. 1), slight scoliosis, Wormian bones of the cranium (Fig. 2), defect of the frontal sinus, hypoplasia of the maxillary sinuses and pseudoprognathism due to a hypoplastic maxillary bone. Laboratory data were not significant.

Oral examination revealed 10 erupted permanent teeth and 2 partially erupted teeth that had appeared about one year before. The right upper central incisor showed hypoplasia with yellowish pigmentation on the labial surface (Fig. 3). The right upper premolar and lower 
anterior teeth showed rotation and malposition. Panoramic radiography revealed 19 completely impacted canines and premolars, including supernumerary teeth (Fig. 4).

The right upper premolar was extracted because it hindered the wearing of dentures.

\section{Observation of the Tooth \\ Macroscopic findings}

The extracted right upper premolar was small, with a length of $15.4 \mathrm{~mm}$ (crown, $6.7 \mathrm{~mm}$ : root, $8.7 \mathrm{~mm}$ ). In form it resembled a lower premolar because of a hypoplastic

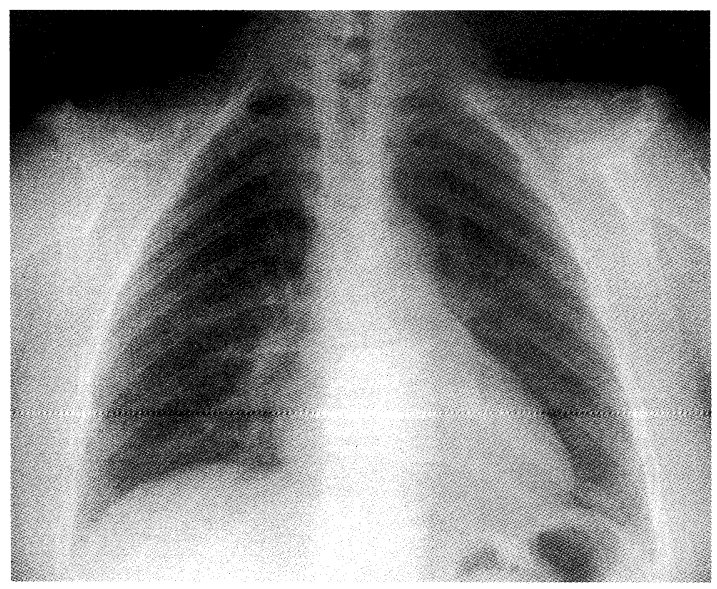

Fig. 1 Post-anterior view of thorax. Partial defects of the bilateral clavicles are evident.

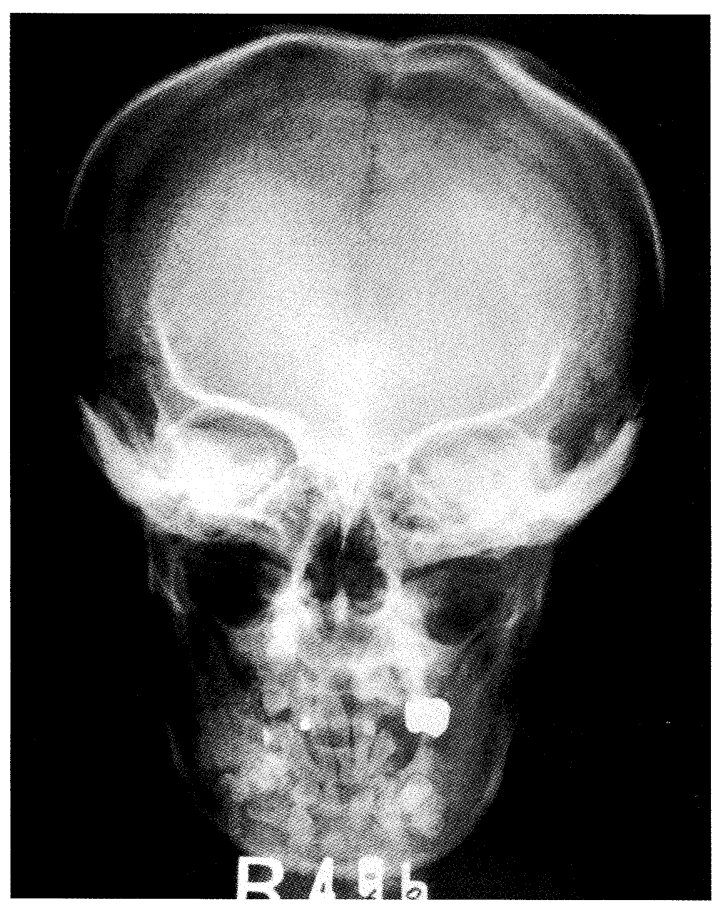

Fig. 2 Post-anterior view of skull. Cranial malformation with multiple Wormian bones. lingual cusp. The apex of the root was slender with slight flexion. Several irregular excavations were scattered on the labial surface, with a slightly yellowish pigmentation (Fig. 5A, B). Radiographic examination revealed the excavations on the labial surface to be dented toward the pulp chamber (Fig. 6A, B).

\section{Microscopic findings}

The tooth was fixed in $10 \%$ neutral formalin and embedded in resin. The ground section was $50 \mu \mathrm{m}$ thick. Microscopic observations revealed enamel hypoplasia on

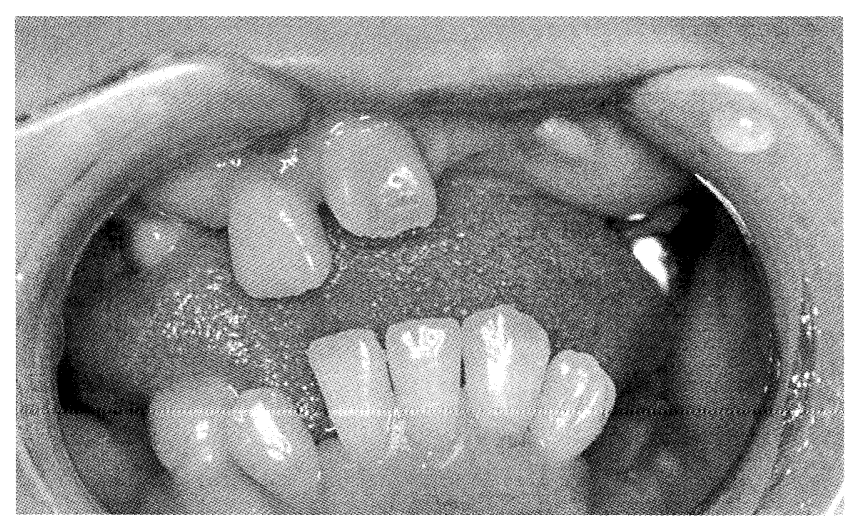

Fig. 3 Intraoral view. Complete and incomplete eruption of erupted permanent teeth. Hypoplasia of the right upper central incisor.

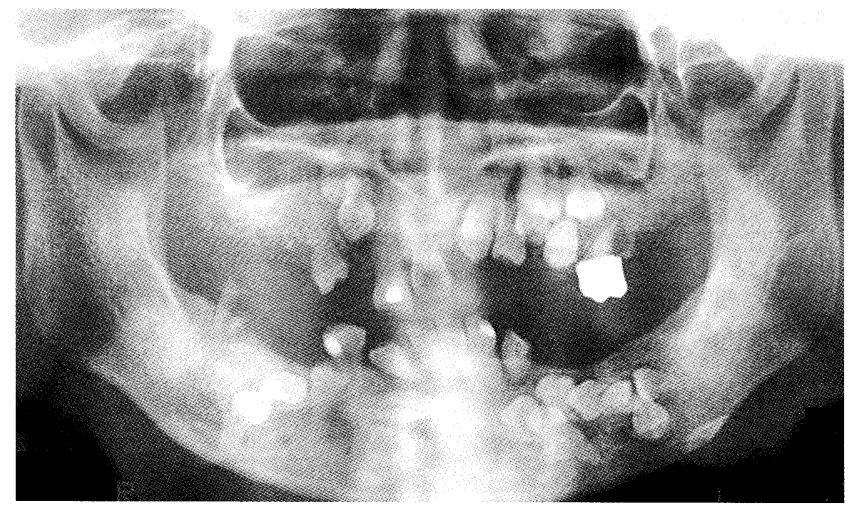

Fig. 4 Panoramic radiograph. Many impacted permanent teeth are present in the maxilla and mandible.

the labial surface of the crown, especially in the cervical region on the labial side (Fig. 7A, B). Enamel hypoplasia was associated with excavation of the dentinoenamel junction toward the pulp chamber. Except for the hypoplastic part, the enamel showed a relatively regular structure with Retzius growth lines, although large enamel 
tufts and wide enamel lamellae were seen in parts. Although the dentinal tubules showed a regular arrangement, interglobular dentin was widely distributed in the crown, and the granular layer of Tomes was prominent in the root. In addition, the incremental von Ebner and counter Owen lines were obscure. Acellular cementum was thick and hyperplastic at the apex and lingual side (Fig. 7A), and no formation of cellular cementum was evident (Fig. 8).

\section{Electron probe X-ray microanalysis}

The cut surface of the tooth, embedded in resin, was

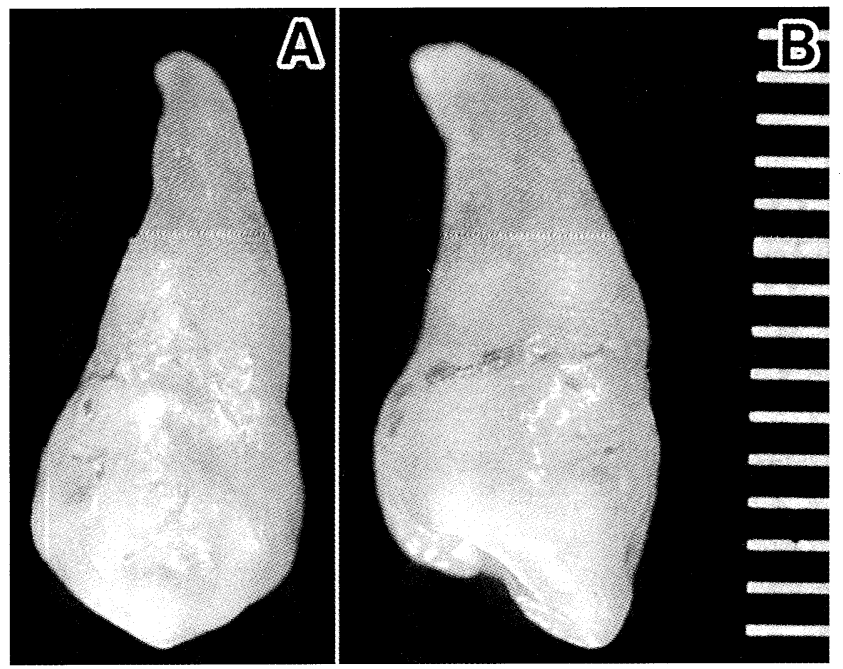

Fig. 5 Macroscopic findings of extracted upper right premolar. There are several irregular excavations of the labial surface with slight pigmentation. 5A, labial surface: $5 \mathrm{~B}$, proximal surface.
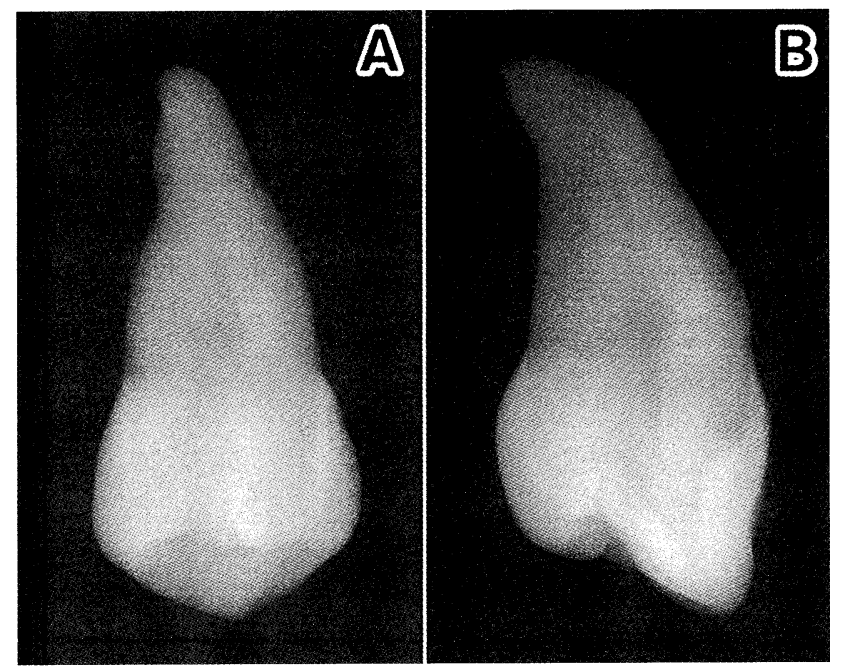

Fig. 6 Radiograph of the upper right premolar. Excavation of the labial enamel dented toward the pulp chamber is seen. $6 \mathrm{~A}$, labio-lingual projection: $6 \mathrm{~B}$, mesio-distal projection. analyzed using an electron probe X-ray microanalyzer (EPMA) (JXA-8900L: JEOL Ltd, Tokyo, Japan). Comparative quantitative analysis of calcium $(\mathrm{Ca})$ and phosphate $(\mathrm{P})$ was performed, using an upper third molar from a healthy 33-year-old woman as a control. In the tooth from the woman with $\mathrm{CCD}$, the quantities of $\mathrm{Ca}$ and $\mathrm{P}$ in enamel and dentin were lower than in that of the control (Fig. 9).

\section{Discussion}

The main oral manifestation of CCD is failure of tooth eruption in the permanent dentition associated with numerous impacted supernumerary teeth. The cause of the eruption failure has been suggested to be heredity, a lack of resorption of the root of deciduous teeth and surrounding bone $(2,4,6,8,10-12)$, and physical obstruction due to numerous impacted supernumerary teeth $(7,11,12)$. In the present case, there were 19 completely impacted teeth, and 2 partially erupted teeth that had appeared about one year previously. We suspected that the partial eruption occurred because of alveolar bone loss caused by aging. Previous studies have reported a lack of cellular cementum in permanent teeth in $\operatorname{CCD}(2,3,5,6,8,9)$, as was found in this case. We suspected that the abnormality of the cementum

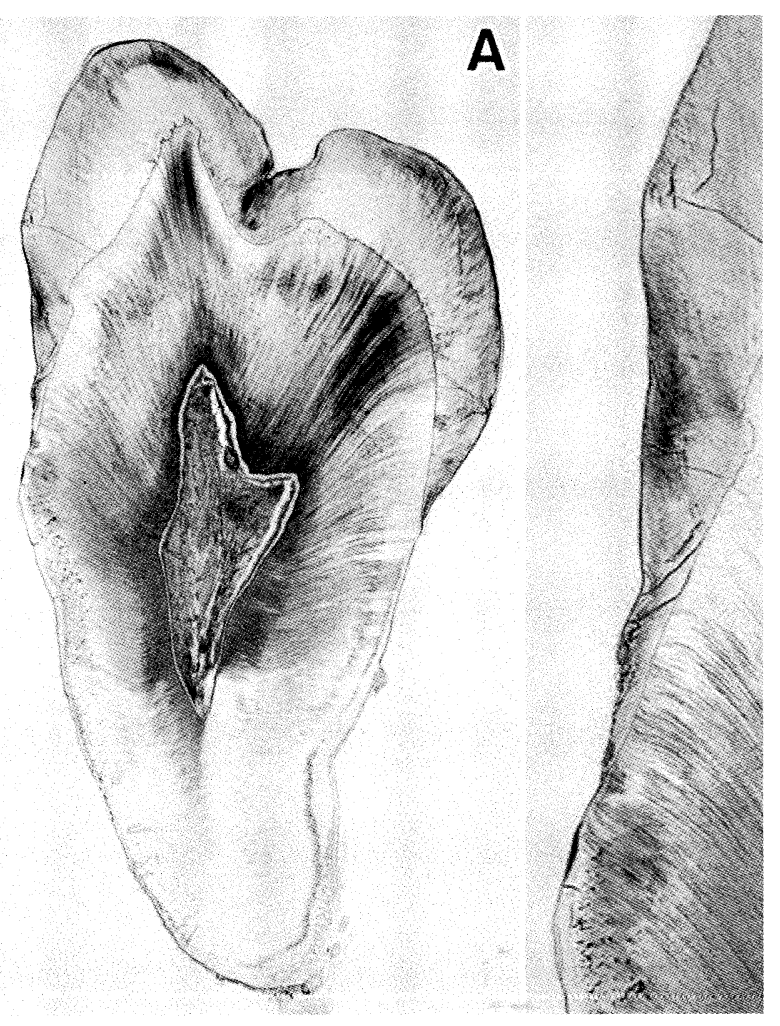

Fig. 7 Microscopic findings of the tooth. Enamel hypoplasia with excavation at the cervical region. Incremental von Ebner and counter Owen lines are obscure (ground section, $\mathrm{A} \times 7, \mathrm{~B} \times 16$ ). 
and the alveolar bone might be related to a disturbance of ossification due to CCD. Recent genetic studies have made it clear that $\mathrm{CCD}$ is produced by an insufficiency of transcription factor CBFA1 in osteoblast differentiation $(13,14)$. However, the relationship between the failure of tooth eruption and the disturbance of osteoblastic differentiation is obscure.

Enamel hypoplasia of deciduous teeth (7) and supernumerary teeth (11) in CCD have been reported. In the permanent tooth of the present case, enamel hypoplasia with yellowish pigmentation and hard-tissue excavation toward the pulp chamber were noted. We suspected that the enamel hypoplasia and excavations were caused by physical pressure from the numerous compacted teeth germs during the development stage of the tooth crown in the permanent dentition and supernumeraries.

We found predominant enamel tufts, interglobular dentin of the crown, and Tomes' granular layer (7,9), which were consistent with a finding of tooth hypocalcification. The quantities of $\mathrm{Ca}$ and $\mathrm{P}$ in the enamel and dentin were lower in CCD than in the control according to EPMA analysis. We suspect that, in addition to the disturbance of bone calcification in $\mathrm{CCD}$, tooth calcification is similarly disturbed.

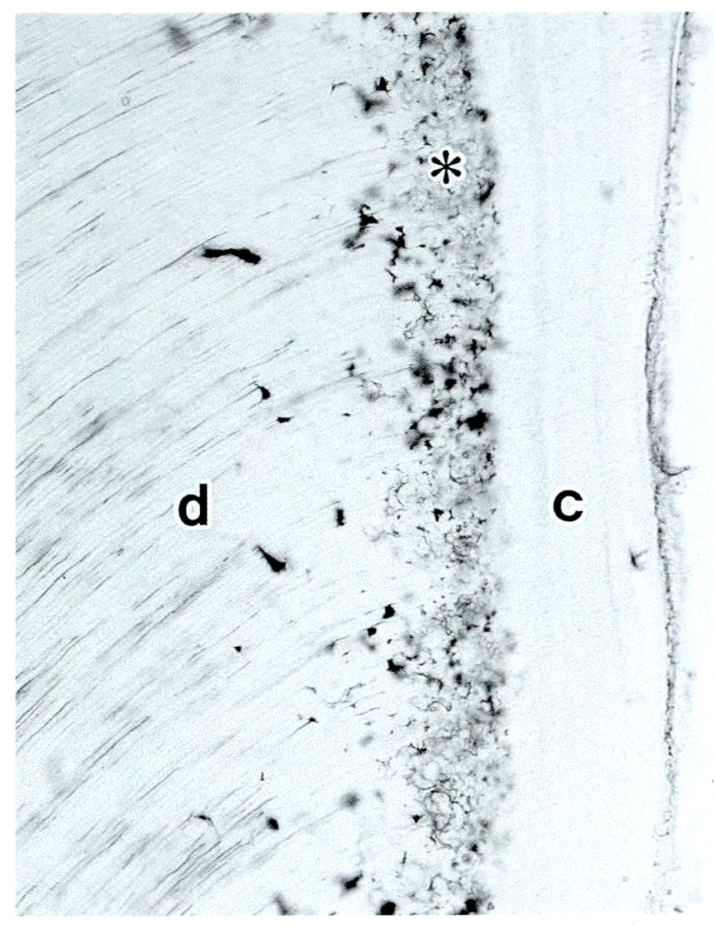

Fig. 8 Microscopic findings. Predominantly Tomes' granular layer $(*)$ and complete lack of cellular cementum $(d$, dentin: c, cementum) (ground section, $\times 100$ ).

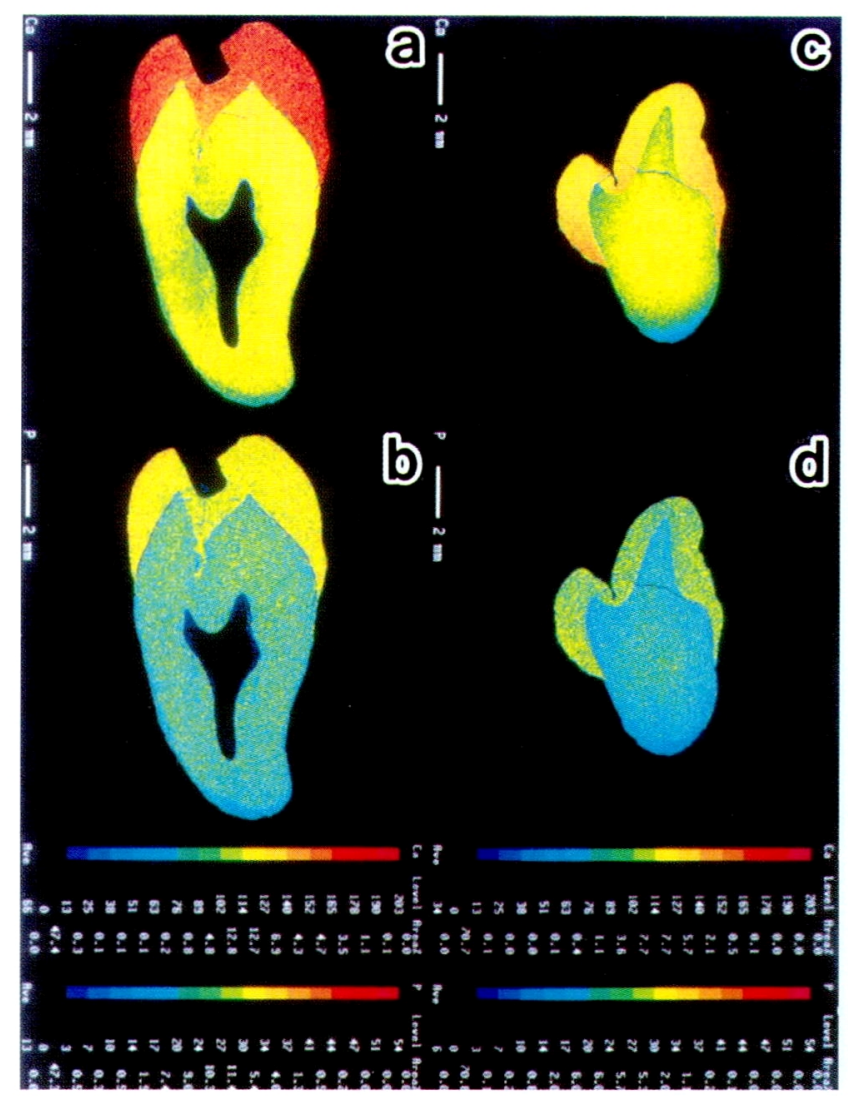

Fig. 9 Electron probe X-ray microanalysis. (a,b, control: c,d, CCD: upper, Ca: lower, P). Ca and $\mathrm{P}$ were less in CCD.

\section{Acknowledgments}

This study was supported by Grants-in-Aid for High Performance Biomedical Materials Research from Ministry of Education, Culture, Sports, Science and Technology, Japan.

\section{References}

1. Gorlin, R.J., Cohen, M.M. and Levin, L.S. (1990) Syndromes of the head and neck. 3rd ed., Oxford University Press, New York, 249-253

2. Rushton, M.A. (1956) An anomaly of cementum in cleido-cranial dysostosis. Br.Dent. J. 100, 81-83

3. Smith, N.H.H. (1968) A histologic study of cementum in a case of cleidocranial dysostosis. Oral Surg. Oral Med. Oral Pathol. 25, 470-478

4. Hitchin, A.D. and Fairley, J.M. (1974) Dental management in cleido-cranial dysostosis. Br. J. Oral Surg. 12, 46-55

5. Hitchin, A.D. (1975) Cementum and other root abnormalities of permanent teeth in cleidocranial dysostosis. Br. Dent J. 139, 313-318

6. Von Gundlach, K.K.H. and Buurman, R. (1978) Dysplasia cleidocranialis. Histologische Befunde am 
Zahnzement. Dtsch. Zahnärztl Z. 33, 574-578 (in German)

7. Yamamoto, H., Sakae, T. and Davies, J.E. (1989) Cleidocranial dysplasia: a light microscope, electron microscope, and crystallographic study. Oral Surg. Oral Med. Oral Pathol. 68, 195-200

8. Dard, M. (1993) Histology of alveolar bone and primary tooth roots in a case of cleidocranial dysplasia. Bull. Group Int. Rech. Sci. Stomatol. Odontol. 36, 101-107

9. Lukinmaa, P-L, Jensen, B.L., Thesleff, I., Andreasen, J.O. and Kreiborg, S. (1995) Histological observations of teeth and periodontal tissues in cleidocranial dysplasia imply increased activity of odontogenic epithelium and abnormal bone remodeling. J. Craniofac. Genet. Dev. Biol. 15, 212221

10. Von Fleischer-Peters, A. (1970) Zur Pathohistologie des Alveolarknochens bei Dysostosis cleidocranialis. Stoma (Heidelb), 23, 212-215 (in German)
11. Migliorisi, J.A. and Blenkinsopp, P.T. (1980) Oral surgical management of cleidocranial dysostosis. $\mathrm{Br}$. J. Oral Surg. 18, 212-220

12. Jensen, B.L. and Kreiborg, S. (1990) Development of the dentition in cleidocranial dysplasia. J. Oral Pathol. Med. 19, 89-93

13. Mundlos, S., Otto, F., Mundlos, C., Mulliken, J. B., Aylsworth, A. S., Albright, S., Lindhout, D., Cole, W. G., Henn, W., Knoll, J. H. M., Owen, M. J., Mertelsmann, R., Zabel, B. U. and Olsen, B.R. (1997) Mutations involving the transcription factor CBFA1 cause cleidocranial dysplasia. Cell 89, 773779

14. Lee, B., Thirunavukkarasu, K., Zhou, L., Pastore, L., Baldini, A., Hecht, J., Geoffroy, V., Ducy, P. and Karsenty, G. (1997) Missense mutations abolishing DNA binding of the osteoblast-specific transcription factor OSF2/CBFA1 in cleidocranial dysplasia. Nat. Genet. 16, 307-310 